\title{
ABC: Evolution, Problems of Implementation and Organizational Variables
}

\author{
Anna Maria Moisello \\ Department of Economics and Business Sciences, University of Pavia, Pavia, Italy. \\ Email: amoisello@eco.unipv.it \\ Received January 25 ${ }^{\text {th }}$, 2012; revised March $2^{\text {nd }}, 2012$; accepted March $14^{\text {th }}, 2012$
}

\begin{abstract}
This paper will reflect on the evolution of the functionality of ABC model, focusing attention on the variables that determine success or failure in its implementation. To this end the paper, through the empirical and theoretical literature review, will: trace the evolution of the ABC model, while highlighting the implications of the implementation process, analyze the concept of success in its implementation and discuss the determinants that influence the outcome, focusing on the organizational variables that firm have to control in order to succeed with ABC.
\end{abstract}

Keywords: Activity Based Costing; Implementation Process; Process Factors; Context Factors

\section{Introduction}

Studies on ABC indicate a contradiction: on the one hand, the model shows considerable potential, which has grown throughout its functionalities evolution, in terms of the benefits that can derive starting from the correct determination of cost and arriving at an effective support to management [1,2]; several studies have shown its success in business practice and an increasing adoption rate [3-7]. On the other hand, various empirical analyzes of the model's implementation reveal a lower than expected success rate regarding its benefits [8,9], a relatively low adoption rate $[9,10]$ different opinions about its effectiveness [11] and some studies on ABC diffusion refer that the number of organizations adopting $A B C$ is not growing and it stopped at a lower than expected level $[12,13]$. It is the so-called ABC paradox [14,15]. The purpose of the paper is to focus-through the empirical and theoretical literature review-the nature of this contradiction and to understand if the success lower than predicted is due to the methodology's limits or to the adopting organizations ones. First of all we will trace the evolution of the model's functionalities to highlight its potentialities in term of effectiveness. Then we will analyze the concept of success of an accounting methodology in order to explain because the studies reach contrasting results. Once defined the concept of success we will consider the determinants of not a success in the model implementation.

\section{The Evolution of the ABC Functionality}

The concept of activity has already been presented in studies by Staubus [16] and Shillinglaw [17], but these works have not directly led either to a series of specific studies or to the spread of the activity approach in business practice. Studies that effectively raised the debate in this area and led to studies on the topic were published only at the end of the 80's. When it was introduced [18], the model had no name, and subsequently became known as "transaction costing" [19]. The term "activity based costing” began to be used in June 1988 by Johnson, and towards the end of 1989 [20] it was shortened to the acronym ABC. Over the years the ABC model has been characterized by an evolution that can be described using stages (Table 1) featuring various objects of analysis which focus on classes of costs of varying magnitude capable of producing utilizable information at different levels of the planning and programming levels [21].

The studies and applications of the model that concern the first stage focus attention on the need to go beyond the limits of traditional methodologies of costing in order to accurately determine the cost of a product, with particular reference to the manufacturing phase. This first stage can, in turn, be divided into three phases characterized by different levels regarding the systematic approach of the ABC model. The first corresponds to the non-formal introductory phase of the method, in which models are drawn up characterized by a varied base for indirect cost imputations and they are not as yet called "activity based" since they are considered complex versions of the traditional systems of cost accounting [22]. In the early 80's the distinctive features of activity based costing compared to traditional methods were identified 
Table 1. ABC evolution stages.

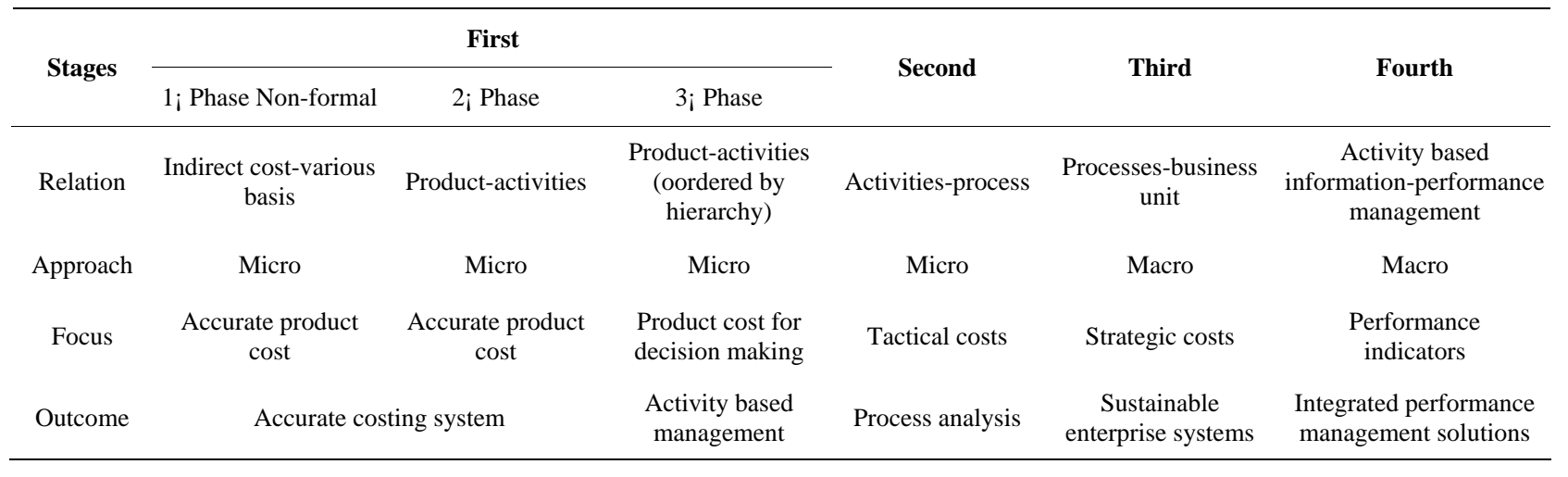

and formally presented in theoretical studies and applications. In this phase the model was applied on an ad hoc basis, without reference to a definite system structure. Beginning midway through the 80's the third phase appeared, characterized by an awareness of the contribution of $\mathrm{ABC}$ to the decision-making process through more correct information on cost and product profitability and by the reaction of the model's proponents to the theoretical criticisms of the model. These criticisms directly refer to the model's assumptions, which can be summarized as follows [23]:

- The total cost can be divided into cost pools, each of which depends on a single cost driver;

- The costs in the cost pools are directly proportional to the level of activity, and thus exclude those functions with a non-linear cost or with a non-zero intercept;

- The activity measures adopted for attributing costs to the individual products can be summed to determine the total volume of the activity, a condition that excludes dependencies among products, such as synergies, interactions, and joint processes.

These are very strong conditions which, when not satisfied, reduce the reliability of activity based cost determination. The theoretical criticisms of the model led Cooper and Kaplan to modify the objectives and the technical characteristics. The concept of resources was modified and a hierarchy in cost classification was introduced; the concept of allocation was replaced by that of estimate; accuracy was no longer considered an objective factor but was interpreted as a subjective judgment; and the objective of the correct determination of cost lost centrality with respect to the other objectives, such as support for the decision-making process [24]. This phase systematically identified the approaches to the implementation of ABC systems as separate systems: the informational needed to construct the model was identified; the methods for recognizing the cost drivers and the criteria for choosing them were defined; and the techniques to classify the aggregation of costs were determined. The third phase produced and made available to companies the specific software for constructing ABC models (in order to undertake the calculations for multiple activities), drivers and products. The evolution of this phase involved the integration of activity based costing and performance measurement [25] through an analysis of the common and unique features of the drivers used as determinants of cost and those used as performance indicators, and through the construction of a system of activity based performance measurement.

The most important contribution of these studies on first generation of models was the emphasis on the concept of cost driver and its relative complexity, bringing to light the distinction between volume driver and drivers linked to transactions, with important implications for many companies regarding the choice of mix [26]. The attention paid to cost drivers as determinants of cost introduces the principle of the control of costs through the control of the respective drivers, which highlights the need to eliminate, through continual improvements, the consumption of drivers that do not produce added value and those activities with no added value. This first generation of activity-based models separately identified the activities and thus did not recognize and reproduce the links between them. The studies and applications emphasize the identification of the cost drivers inside the business units; in this phase the applications are meant to concentrate on the efficient use of the resources, and thus there is a stress on the link between the cost drivers and resource consumption; however, the link with the processes is not brought out.

The second stage of ABC models shifts the focus from product to process. While the first stage models started with the identification of the activities to which the costs were associated, in the second ones the initial step was to identify the processes-productivity, sales, distribution and administration - and then to match up the activities with the processes. First generation models were aimed to correct the error in overhead allocation to product related to cost accounting systems, but continued development made clear that ABC was applicable beyond the 
original aim [28]. The models produced in this phase represent an extension of those in the first, since they are still focused on the internal activities and offer an analysis of tactical costs, but not yet of strategic ones [21].

The information for strategic planning is provided in the third stage models, which extend the analysis beyond the internal activities to also include those external to the business unit. The systems produced in this phase trace the relation between activities and processes and then between processes and business units as a focus of attention.

The aim of the models in this phase is to support the firm's competitive strategy through the chain of value and thus to highlight the contribution in terms of value creation of both the internal activities and those which are upstream and downstream for the organization. This phase brings out the role of the support activities in contributing to achieving competitive advantage, while these activities are not explicitly included in the first and second phase models. Activity based logic moves beyond the limited focus on the improvement of efficiency and is interpreted as key to building a database that can support the strategic processes with regard to elements upstream-clients, clusters, distribution channels-as well as downstream-suppliers. The evolution of this generation of models saw a shift from the micro to the macro approach and the development of ABC systems aimed at supporting the entire firm through the modeling of the relations between the activities and the various business units. The difficulty in extending the approach to the entire firm, especially where there was a desire to maintain the capacity to reflect on the variations in the activities, processes, clients and products comes from the enormous volume of analyses and interviews that must be undertaken to realize the model and maintain it up to date [25]. This leads, on the one hand, to a barrier to adopting the model in an extensive manner, and on the other, where the firm opts for such an extension, to a non-optimal frequency in updating the model due to the high costs for determining and analyzing the drivers, thereby affecting the correct determination of costs and thus the informational efficiency in support of the decision-making process.

The choice and determination of the drivers represent the crux of the complexity and criticalness of the ABC model; thus tied to this stage are many of the difficulties uncovered in implementing the model and extending it to the entire firm. In designing the model firms can choose drivers linked to the number of transactions undertaken or to their duration. Normally the former are used, since measurement in this case is less onerous; however, the latter are more appropriate when the transactions generated by the macro-activities imply differing levels of complexity. Based on this observation Kaplan and
Anderson [25] have proposed a "time-driven" version of the model. This model follows the logic of the traditional one, differing in the way it calculates the unit costs of the activities, which are determined in relation to the utilization cost of the capacity in the unit of time and to the number of units of time required by the transaction, that is assumed as the driver in attributing the costs of the activities to the final object. We know that various levels of complexity can characterize the transactions; that is, they can require a different number of activities or a different intensity of utilization with respect to another activity, thereby causing variations in duration. According to the traditional approach, the correct attribution of activity costs is obtained by breaking up the activity into the various combinations of activities that may be required in the various situations. The time-driven model simplifies the solution to the problem by defining the duration of the activity as the sum of the individual activities required [26]. This eliminates the first step in the implementation process of the traditional $\mathrm{ABC}$ model that is, the determination of the different activities; it simplifies the costing process, since it is no longer necessary to interview the operators in order to allocate the resource costs to the activities; and explicitly sets out the costs of the unutilized capacity [27]. This provides important indications to management in terms of the efficiency in the use of productive capacity, thereby highlighting the appropriateness of using or eliminating the excess capacity. The approach based on duration also simplifies the problem of updating the model and thus of the level of detail. For example, a high level of detail can be achieved by increasing the number of the activities, with the only requirement being to estimate the respective unit times, without redoing the interviews, by asking the personnel for estimates of the use of their overall time based on a new activity distribution. The model has important flexibility features, which make it efficient and effective when utilized. It easily combines with the data available from the ERP and CRM systems and, as mentioned above, it can more easily be extended to the entire firm and adapted to variations in the levels of complexity of the activities and of the final objects of costs, such as products, services, clients or distribution channels. Thus the time-based algorithms to measure complexity together with the new methods that have emerged — such as web-based surveys and the use of "extract, transform and load" technology to integrate ABC with data sourcesreduce the cost of implementation. Thus in this third stage new uses of $A B C$ have appeared that increase the value derived from the tool: shared services pricing models for IT and other corporate functions to support service legal agreements with business units, target costing for product design, optimization of logistics, supply chain and IT investment, and minimization of the total 
cost of ownership of equipment and other assets [28].

According to Turney [28], the use of ABC as an integral component of business performance management solutions is peculiar to the fourth stage: ABC becomes a multifaceted algorithm and database for financial and organizational information. New profitability management tools depend upon $\mathrm{ABC}$ information to increase analytic power and to improve their effectiveness. ABC is an important source of performance measure in organizations that integrate $\mathrm{ABC}$ with performance management: in the process dimension of a scorecard, activity cost provides the focal point for target setting and the scoring of goals around process performance. From the financial planning point of view, ABC models-combined with forecasting and analytic techniques to support fact-based scenario development-support the formulation of long-term plans and budgets consistent with the optimization of process performance. ABC today also plays an important role in human capital management [28]. It is an effective tool to analyze high cost processes and improvement measures to free up resources that may be redeployed to satisfy critical needs. ABC can be used to forecast the transaction level of activities, which is then used to forecast the amount of resources used to perform the new level of activities. It can also be used to perform statistical forecasting to accurately determine the number of people required to support targeted products, customers, channels, and so on. Nowadays some organizations are using $\mathrm{ABC}$ to relate sustainability with profitability; for example, they use the model to measure and report the use of carbon dioxide alongside costs, tracking sources of carbon to the resources that consume carbon [28].

\section{The Concept of Success in Implementation}

In order to evaluate the success of the implementation of an $A B C$ project it is necessary above all to define what is meant by success. In terms of management accounting, the success concept is generally multi-dimensional and dynamic [29]. The multi-dimensional feature derives from the various functions which management accounting can carry out and from the different variables that influence its effectiveness, such as the characteristics of the information produced, the processes that produce the information, its possible uses, and the effects of such utilization. It is dynamic in that it changes over time in relation to the evolutionary stages of systems, and in space based on the perspective of the person doing the evaluation. The opinion can differ depending on whether it is formulated by the producer or by the person or persons who will use the information and as a function of the hierarchical position of the person making the evaluation.
The empirical studies reveal different points of view, and these contrasting results are partly due to the different definition of success the evaluation is based on and to the different means of measurement [30]. The methodology by activities is adopted for various objectives; the effectiveness and success of the implementation are properly appreciated only if they enable the firm to compare the objectives achieved with those set out by the organization, not with an objective exogenously taken as a benchmark in terms of the context in question. Thus the same implementation experience can be evaluated differently depending on the criterion adopted and the stakeholder for the information produced: in the organization itself managers from different hierarchical levels can have opposing views of success or failure based on how they use the information [10]. There are three levels regarding the objectives and modes of utilization of the activity approach [14]: the analysis of the activities, the determination of the cost of the activity, or true activity based costing, in ascending order, since each level of approach assumes that the previous level has also been adopted. This implies that the results from implementation must be compared with those that are coherent with the chosen level of adoption. Only a few of the empirical studies present this distinction, which can explain the contradictions that have emerged.

There are four basic types of approaches used to measure success [30]. The first approach [3,5,31] uses management's evaluation of the global success of the project based on a limited number of attributes of success and without distinguishing the different levels of adoption. The second $[32,33]$ the success obtained by determining a certain number of implementation phases and basing the evaluation on the phase that is achieved, implicitly assuming that the objective of each organization is to realize the $\mathrm{ABC}$ in a narrow sense, excluding the possibility that it could involve intermediate implementation levels. The third approach [4] bases the evaluation of success on four measures: the scope of use of the ABCM information in the decision-making process, changes in decisions based on the ABCM information, the impact of the $\mathrm{ABCM}$ on revenues and costs, and management's evaluation of the impact of the ABCM. This study carefully examines the link between ABCM information and company performance, but does not place measurement in relation to the level and objective of use. The fourth [30] starts from a multi-level view of the model's adoption, in line with Gosselin's approach [14], and recognizes that organizations can pursue different objectives and choose different levels of implementation, and thus not evaluate success on the basis of the phase reached but in relation to a set of criteria and benchmarks which are coherent with the chosen level. 


\section{The Determinants of Success or Failure of the Model's Implementation}

Let's analyze the determinants of the cases of failure of the implementation. The empirical literature on the topic has for a long time now linked success in the implementation of an ABC system with technical and behavioral factors [34-40]; several authors have suggested that an important obstacle to successful implementation of $A B C$ is a lack of attention to behavioral factors [4,5,31,33, 41-44]. Studies that propose analyzing ABC implementation by means of process theories hypothesize that the success of the project depends on the implementation process and on context factors linked to the environment. Process factors, such as management support and involvement and the resources available in carrying out the project, influence the evaluation of the ABC system. The context factors, represented by the characteristics of the individuals involved in innovation and of the environment, such as the salary structure, expectations about the latter, and the quality of existing information systems, in turn influence the implementation process and the evaluation of the resulting ABC system. The degree of importance of these behavioral and organizational factors in the success of $A B C$ is different at different stages of $\mathrm{ABC}$ implementation, and cultural differences play an important role in ABC implementation strategies [44].

Empirical studies [43] have shown that even though the implementation process influences the results of the process itself, both the process and the results are strongly influenced by the context. According to these studies, the evaluation of an $\mathrm{ABC}$ system depends on the process through which an organization develops and obtains support for the system from those operating from within. For example, it is more likely that managers will support the $\mathrm{ABC}$ implementation process when they expect a higher salary from good performance.

The failure in implementing an ABC system is in large part due to exogenous context factors rather than to the implementation process itself $[8,43]$. Shields states that the problems firms have had in implementing $\mathrm{ABC}$ are in large part due to their extreme focus on the model's architecture and the design of the appropriate software while neglecting the behavioral and organizational factors involved in the process. The context factors are represented by strategy and the organization. The type of strategy chosen influences the need for innovation in the management of the activities while the organizational structure influences the organization's ability to implement the innovations. Studies by Gosselin [14] analyze the adoption of $\mathrm{ABC}$ with regard to the two variables and, from the strategy point of view, refer to the following classification that distinguishes firms in terms of changes in products and markets [45]:
- Explorers: characterized by a dynamic approach to seeking out new markets and by the offering of new products that can satisfy consumer expectations;

- Defensive: this group operates in a context of limited product range and market, with high production volumes and a low level of diversification;

- Analytic: with characteristics that fall between those of the two preceding categories;

- Reactive: this group has no predefined strategy.

The results of the empirical analysis reveal a greater predisposition to adopting the analysis by activity approach by the management of explorer organizations since, being innovative, the latter tend to adopt innovations not only in the area of operations management but in the accounting area as well. Gosselin's analysis also shows the role of the organizational structure in the choice of level regarding the approach for the activity to be adopted-analysis of the activities, determination of the cost of the activity, or true activity based costingand shows that in firms that choose to adopt $A B C$ there is a significant shift to a true implementation of the model in centralized, formal structures, since these are based on formal systems. The theoretical studies [46-49] assign an important role in the success of the implementation to the organizational culture, such as an outcome and team orientation and a propensity to innovate. The empirical studies [30] confirm the relevance of an outcomes orientation, since such organizations are wont to eagerly embrace practices that can increase performance and to pursue these diligently; the studies do not reveal a positive correlation with an innovating attitude, justify this with the consideration that this characteristic spurs firms to utilize new methodologies but not to support these once they are adopted. Finally, the studies find no relation between a team orientation and success, and, unlike the theoretical studies, do not clarify this contrast.

An additional and important context factor for success is the existence of a link with quality improvement initiatives, and for two reasons. On the one hand, if the activity based information supports quality programs, then this takes on greater importance in the decision-making process and thus leads to greater success for the project. On the other hand, the adoption of the model has potentially greater success when quality support initiatives are already in place since, with part of the process analysis required for $\mathrm{ABC}$ implementation already having been undertaken, the information gathering phase is less complex and burdensome. In general the user's perception of the accounting techniques adopted depends on the level of support offered by such techniques to the other management instruments [50]. This view is supported by the results of a study by Baird et al. [30], which shows a correlation between the degree of use of the model and the perceived amount of success, independently of the 
model's approach level: that is, activities analysis, determination of activity cost, or activity based costing, divided into the various objects of cost. These results are also interesting because they show that the success perceived does not depend on the adoption level; therefore, the decision by the organization not to move to the last implementation level may be a conscious and satisfactory one [30].

\section{The Organization's Willingness to Accept the ABC Project}

The adoption of ABC represents a program of organizational change that often is not adequately recognized and administered by management [51]. The success of the system's implementation depends on the leadership qualities of the person who carried forward the project and by the organization's capacity to be ready to welcome change. A fundamental role in implementation failure is played by the resistance of the persons concerned to accept the model and collaborate in its construction, a resistance that derives from several factors. One is the fear of providing information which, derived from a new accounting model, might provide new parameters for determining failure and success, thereby leading to interference in the practices carried out or undermining the latter's authority. This first factor derives from two aspects: the diffidence toward an unknown model and the worry that inefficiencies might be uncovered. A second factor that creates inertia in the adoption of the model by employees operating at various levels is the heavy job of gathering and processing the required data. Since the model is much more detailed and complex than traditional cost accounting systems, there is a considerable effort in terms of information gathering regarding the activities to identify and aggregate into activity pools, on the one hand, and the measurement and analysis of cost driver trends through statistical analysis on the other. This work is particularly onerous during the initial phase, when it may not be clear what information is needed and there is the risk of excessive data gathering, thereby overtaxing the information systems and the employees [51].

Nair [52] had efficiently modeled the process to follow in order to evaluate and create inside the organization the willingness to react positively to the ABC project, highlighting, in the various phases of the project, the variables that can have a crucial influence on the implementation result, thereby determining its success or failure. The model identifies four important steps in measuring the organization's capacity to direct the project. If adequately managed, these steps contribute to the success of the project's implementation:

- Gathering the basic elements for starting the imple- mentation;

- Seeing that the program is aligned with the organization's personality;

- Informing the firm;

- Transforming the consensus into a commitment.

The fundamental assumptions for implementation are vision, the ability to see and structure the way the project should function, and knowledge, an awareness based on analysis and experience. This means that the project's promoters must identify the sources of the above elements within the firm so as make them available during the model's development.

The second step assumes an understanding of how the organization adopts new ideas and processes, and thus focuses on the point of view from which to assess the new initiatives. Organizations are focused on different variables; better yet, on the mix of variables to which difference emphasis is given. Organizations can thus be focused on individuals, processes or technology, presenting only one of these viewpoints or a mix that determine its “personality”. Outlining the organization's personality reveal the guidelines which must be followed in order to introduce activity based logic and techniques, allowing objectives to be introduced that are coherent with what is perceived as the focus.

The third step represents one of the most difficult and important, and it consists in educating those working within the firm at all levels about the principles and functioning of $\mathrm{ABC}$, since the sharing of objectives and an awareness of the role of $\mathrm{ABC}$ in their achievement are basic to an effective implementation [53]. In fact, several empirical studies show a correlation between commitment to training and project success [4,5,33]. For example, Anderson et al. [42] state that training not only has the benefit of improving technical knowledge but also influences how team members see the ABC model development task. Chenhall [54] states that training and clarity of objectives during implementation enhances cognitive conflict, which is then associated with ABC successful applications. From the operational point of view there is a need to train managers and employees throughout the organizational hierarchy to spread the objectives, logic and practices of the model so as to clarify its utility, remove the suspicion that it can only worsen the work load, and create a shared commitment to its adoption. A complex learning process can be used to remove organizational resistance and defensive behavior toward the adoption of ABC [55]. The education of individuals must be carried out using the knowledge of the organization's learning processes. The effectiveness of this educational process depends on the training techniques and the learning and communication methodologies used, which implies the need to analyze the behavior of the users of the information, that is, to observe the 
approach to and way of dealing with the information so as to construct a map of the preferred instruments for the information transfer. Once ABC is adopted it will be successful if there continues to be the motivation to use the information from the model in order to make management more effective; the systems should be linked to the ABC determinations [49,56], and those within the firm should be aware of this. The relation between the success of the implementation and the evaluation and remuneration of performance is justified by the fact that, if the evaluation and remuneration are directly linked to the information produced by the activity based system, then this information will be used [30]. This argument is, in turn, based on the hypothesis-which was confirmed in the activity management case in the studies by Anderson [32], Shields [31], and Foster and Swenson [4] - that the behavior of the firm's personnel is influenced by the way their performance is evaluated and remunerated.

The fourth factor is the transformation, by the team directing the project and by top management, of the general agreement into a true commitment to achieving the objectives. In fact, the project's success is correlated to the support provided by top management [32,4,8,57] through their authority and the resources the task entails. In fact, it is crucial that, on the one hand, top management participate in the process whereby the implementation objectives are communicated and intervene, where necessary, to remove any obstacles, and on the other that they support the project by making an adequate amount of resources available for the project [5].

\section{Conclusions}

This paper - through the analysis of the evolution of activity based costing functionality-focuses a contradiction: why on the one hand its possibilities of use and application are growing and on the other hand theoretical and practical studies do not show a unanimous opinion of success and a level of adoption of the model consistent with its potentialities? This work answers pointing out two aspects: first of all ABC studies has different concept of success: they measure different things so they have different results and it is not a paradox. Second companies who experience the model at the same level of implementation actually have different results depending on how they handle the organizational variables.

The analyses carried out show the role of the three variables that condition implementation of the model: the capacity to implement innovations, leadership from those carrying out the project, and the behavior of those within the organization. The capacity to operationalize innovations depends on the organizational culture and structure, which in turn are strongly tied to the firm's strategic orientation. An innovation-minded firm has a culture open to change and a flexible organizational structure; thus, it is able to accept or support the introduction of new methodologies. The leadership of those promoting the project is very important from two points of view. First, it leads to top management's support in terms of staffing and funding, even when the introduction of the project does not come directly from them. These two forms of support take on particular importance when the project impacts the firm's information systems, where resistance to change is normally quite high due to the rigidity of systems and the cost and time the changes entail. For this reason it is important in such situations that the project be assigned the necessary human and quantitative/quailtative resources. The second effect that derives from the leadership qualities of those promoting and directing the project is the improvement in the level of acceptance and shared commitment to the project within the organization. Acceptance of the project can be slowed down by the weight of the data collection activity it requires on the one hand, and on the other by a general diffidence by individuals toward the adoption of new models. The effect of the first factor can be mitigated by adopting time driven ABC, which, as observed above, allows for the streamlining of the data gathering activity and the simplification of the model's updating. The attitude of individuals concerning the use of the model and their behavior in this regard must instead be controlled through appropriate operational mechanisms. The objectives of ABC adoption must be presented through communication and training so that they are shared by the organization and pursued under the stimulus of an effective incentives system. To this end, it is important that the acceptance of the project be motivated by an expectation regarding remunerations that depends on an evaluation explicitly based on the achievement of the ABC objectives. ABC can offer considerable advantages for the organization as long as the latter is able to seize the opportunity by dedicating the necessary commitment to administrative innovation.

\section{REFERENCES}

[1] J. Innes and F. Mitchell, “The Process of Change in Management Accounting: Some Field Studies Evidence,” Management Accounting Research, Vol. 1, 1990, pp. 3-19. doi:10.1016/S1044-5005(90)70042-X

[2] H. T. Johnson, "Beyond Product Costing: A Challenge to Cost Management Conventional Wisdom," Journal of Cost Management, Vol. 4, No. 3, 1990, pp. 15-21.

[3] D. Swenson, "The Benefits of Activity Based Cost Management to the Manufacturing Industry," Journal of Management Accounting Research, Vol. 7, No. 4, 1995, pp. 167-180.

[4] G. Foster and D. W. Swenson, "Measuring the Success of Activity-Based Cost Management and Its Determinants," 
Journal of Management Accounting Research, Vol. 9, 1997, pp. 109-141.

[5] A. S. McGowan and T. P. Klammer, "Satisfaction with Activity-Based Cost Management Implementation,” Journal of Management Accounting Research, Vol. 9, 1997, pp. 217-237.

[6] A. Bhimani, M. Gosselin and M. Ncube, "Strategy and Activity-Based Costing: A Cross National Study of Process and Outcome Contingencies," International Journal of Accounting, Auditing and Performance Evaluation, Vol. 2, No. 3, 2005, pp. 187-205. doi:10.1504/IJAAPE.2005.007672

[7] L. Cinquini, P. Collini, A. Marelli and A. Tenucci, “An Exploration on Factors Affecting the Diffusion of Advanced Costing Technique: A Comparative Analysis of Two Surveys (1996-2005)," Proceedings of the 31st Annual Congress of the European Accounting Association, Rotterdam, 23-25 April 2008.

[8] T. Malmi, "Towards Explaining Activity-Based Costing: Accounting and Control in Decentralized Organization,” Management Accounting Research, Vol. 4, No. 4, 1997, pp. 459-480. doi:10.1006/mare.1997.0057

[9] J. Innes, F. Mitchell and D. Sinclair, “Activity-Based Costing in the UK's Largest Companies: A Comparison of 1994 and 1999 Survey Results," Management Accounting Research, Vol. 11, No. 3, 2000, pp. 349-362. doi:10.1006/mare.2000.0135

[10] W. D. J. Cotton, S. M. Jackman and R. A. Brown, “ Note on a New Zealand Replication of the Innes et al. UK Activity-Based Costing Survey," Management Accounting Research, Vol. 14, No. 1, 2003, pp. 67-72. doi:10.1016/S1044-5005(02)00057-4

[11] D. Cagwin and M. Bouwman, "The Association between Activity-Based Costing and Improvement in Financial Performance," Management Accounting Research, Vol. 13, No. 1, 2002, pp. 1-39. doi:10.1006/mare.2001.0175

[12] B. Pierce, “Activity-Based Costing: The Irish Experience: True Innovation or Passing Fad?” Accountancy Ireland, Vol. 36, No. 5, 2004, pp. 28-31.

[13] R. A. Lawson, "The Use of Activity-Based Costing in the Healthcare Industry: 1994 vs 2004,” Research in Healthcare Financial Management, Vol. 10, No. 1, 2005, pp. 7794.

[14] M. Gosselin, “The Effect of Strategy and Organizational Structure on the Adoption and Implementation of Activity-Based Costing," Accounting Organization and Society, Vol. 22, No. 2, 1997, pp. 105-122. doi:10.1016/S0361-3682(96)00031-1

[15] T. Kennedy and J. Affleck-Graves, "The Impact of Activity-Based Costing on Firm Performance," Journal of Management Accounting Research, Vol. 13, No. 1, 2001, pp. 19-45. doi:10.2308/jmar.2001.13.1.19

[16] G. Staubus, “Activity Costing and Input-Output Accounting,” R. D. Irwin, Inc., Homewood, 1971.

[17] G. Shillinglaw, “Managerial Cost Accounting,” R. D. Irwin, Inc., Homewood, 1982.

[18] H. T. Johnson and R. S. Kaplan, "Relevance Lost Rise and Fall of Management Accounting," Harvard Business
School Press, Boston, 1987.

[19] R. Cooper and R. S. Kaplan, "How Cost Accounting Distorts Product Costs,” Management Accounting, Vol. 69, No. 10, 1988, pp. 20-27.

[20] R. Cooper, "The Rise of Activity-Based Costing-Part Three: How Many Cost Drivers Do You Need and How Do You Select Them?” Journal of Cost Management, Vol. 2, No. 4, 1989, pp. 34-46.

[21] C. D. Mecimore and A. T. Bell, “Are We Ready for Fourth Generation ABC?” Management Accounting, Vol. 76, No. 1, 1995, pp. 22-26.

[22] R. B. Troxel and M. G. Weber, "The Evolution of Activity Based Costing," Journal of Cost Management for the Manufacturing Industry, Vol. 7, No. 2, 1990, pp. 14-22.

[23] E. Noreen, "Conditions under Which Activity-Based Cost Systems Provide Relevant Costs," Journal of Management Accounting Research, Vol. 3, No. 4, 1991, pp. 159168.

[24] T. C. Jones and D. Dugdale, "The ABC Bandwagon and the Juggernaut of Modernity," Accounting, Organization and Society, Vol. 27, No. 1\&2, 2002, pp. 121-163.

[25] R. S. Kaplan and S. R. Anderson, "Time-Driven Activity Based Costing,” Harvard Business Review, Vol. 82, No. 11, 2004, pp. 131-138.

[26] P. Everaert and W. Bruggeman, "Time-Driven ActivityBased Costing: Exploring the Underlying Model,” Cost Management, Vol. 21, No. 2, 2007, pp. 16-20.

[27] M. Namazi, "Performance-Focused ABC: A Third Generation of Activity-Based Costing System," Cost Management, Vol. 23, No. 5, 2009, pp. 34-46.

[28] P. B. Turney, “Activity-Based Costing: An Emerging Foundation for Performance Management," Cost Management, No. 4, 2010, pp. 33-42.

[29] L. Cinquini and F. Mitchell, "Success in Management Accounting: Lessons from the Activity-Based Costing/Management Experience,” Journal of Accounting and Organizational Change, Vol. 1, No. 1, 2005, pp. 63-78. doi:10.1108/18325910510635290

[30] K. Baird, G. Harrison and R. Reeve, "Success of Activity Management Practices: The Influence of Organizational and Cultural Factors,” Accounting \& Finance, Vol. 47, No. 1, 2007, pp. 47-67. doi:10.1111/j.1467-629X.2006.00195.x

[31] M. D. Shields, “An Empirical Analysis of Firms’ Implementation Experiences with Activity-Based Costing," Journal of Management and Accounting Research, Vol. 7, No. 4, 1995, pp. 148-166.

[32] S. W. Anderson, "A Framework for Assessing Cost Management System Changes: The Case of Activity-Based Costing Implementation at General Motors, 1986-1993,” Journal of Management Accounting Research, Vol. 7, No. 4, 1995, pp. 1-51.

[33] K. R. Krumwiede, "The Implementation Stages of Activity-Based Costing and the Impact of Contextual and Organizational Factors,” Journal of Management Accounting Research, Vol. 10, 1998, pp. 239-277.

[34] R. Cooper, "Implementing an Activity-Based Cost System,” Journal of Cost Management, Vol. 4, No. 1, 1990, 
pp. 33-42.

[35] R. G. Eiler and J. P. Campi, "Implementing Activity-Based Costing at a Process Company," Journal of Cost Management, Vol. 4, No. 1, 1990, pp. 43-50.

[36] I. K. Kleinsorge and R. D. Tanner, “Activity-Based Costing: Eight Questions to Answer before You Implement," Journal of Cost Management, Vol. 5, No. 3, 1991, pp. 8488.

[37] L. F. Jones, "Product Costing at Caterpillar," Management Accounting, Vol. 71, No. 8, 1991, pp. 34-42.

[38] H. K. Drumeller, "Making Activity-Based Costing Practical,” Journal of Cost Management, Vol. 7, No. 2, 1993, pp. 21-27.

[39] G. J. Beaujon and V. R. Singhal, "Understanding the Activity Cost in an Activity Based Cost System,” Journal of Cost Management, Vol. 4, No. 1, 1990, pp. 51-72.

[40] M. Al-Omiri and C. Drury, "A Survey of Factors Influencing the Choice of Product Costing Systems in UK Organizations,” Management Accounting Research, Vol. 18, No. 4, 2007, pp. 399-424. doi:10.1016/j.mar.2007.02.002

[41] C. Argyris and R. S. Kaplan, "Implementing New Knowledge: The Case of Activity-Based Costing," Accounting Horizons, Vol. 8, No. 3, 1994, pp. 83-105.

[42] S. W. Anderson, J. W. Hesford and S. M. Young, "Factors Influencing the Performance of Activity-Based Costing Teams: A Field Study of ABC Model Development Time in the Automobile Industry," Accounting, Organization and Society, Vol. 27, No. 3, 2002, pp. 195-211. doi:10.1016/S0361-3682(01)00057-5

[43] S. W. Anderson and S. M. Young, "The Impact of Contextual and Process Factors on the Evaluation of Activity-Based Costing Systems," Accounting, Organizations and Society, Vol. 24, No. 7, 1999, pp. 525-559. doi:10.1016/S0361-3682(99)00018-5

[44] M. S. Velmurugan, "The Success and Failure of ActivityBased Costing Systems,” The Journal of Performance Management, 2010.

[45] R. E. Miles and C. C. Snow, "Fit, Failure and the Hall of Fame,” Free Press, New York, 1994.

[46] L. D. Parker, “The Dynamics of 'New' Management Con- trol Systems: International Perspectives,” Accounting Research Journal, Vol. 10, No. 2, 1997, pp. 116-124.

[47] S. P. Landry, L. M. Wood and T. M. Lindquist, "Can ABC Bring Mixed Results?” Management Accounting, Vol. 78, No. 2, 1997, pp. 28-33.

[48] M. Gering, “Activity-Based Costing Lessons Learned Implementing ABC,” Management Accounting, Vol. 77, No. 5, 1999, pp. 26-27.

[49] R. Drake, S. F. Haka and S. P. Ravencroft, "Cost System and Incentive Structure Effects on Innovation, Efficiency and Profitability in Teams," Accounting Review, Vol. 74, No. 3, 1999, pp. 93-112. doi:10.2308/accr.1999.74.3.323

[50] G. Norris, "User Perceptions of an Application of Activity-Based Costing," Advances in Management Accounting, Vol. 3, 1994, pp. 139-177.

[51] J. A. Ness and T. G. Cucuzza, "Tapping the Full Potential of ABC,” Harvard Business Review, Vol. 73, No. 4, 1995, pp. 130-138.

[52] M. Nair, "Helping Ensure Successful Implementations of Activity-Based Management," Journal of Corporate Accounting \& Finance, Vol. 13, No. 2, 2002, pp. 73-86. doi:10.1002/jcaf.1226

[53] A. M. Moisello, "Managerial an Accounting Aspects of Transfer Prices: A Case in the Shipping Sector,” The International Journal of Knowledge, Culture \& Change, Vol. 10, No. 12, 2011, pp. 143-153.

[54] R. H. Chenhall, "The Role of Cognitive and Affective Conflict in Early Implementation of Activity-Based Management," Behavioral Research in Accounting, Vol. 16, No. 1, 2004, pp. 19-44. doi:10.2308/bria.2004.16.1.19

[55] M. S. Velmurugan and W. N. A. B. W. Nahar, "Factors Determining the Success or Failure of ABC Implementation,” Cost Management, No. 5, 2010, pp. 35-46.

[56] A. R. Drake, S. F. Haka and S. P. Ravenscroft, "An ABC Simulation Focusing on Incentives and Innovation," Issues in Accounting Education, Vol. 16, No. 3, 2001, pp. 443-471. doi:10.2308/iace.2001.16.3.443

[57] K. R. Krumwiede, “ABC: Why It's Tried and How It Succeeds,” Journal of Management Accounting Research, Vol. 79, No. 4, 1998, pp. 32-38. 